\title{
Short communication: Effects of Bos taurus autosome 9-located quantitative trait loci haplotypes on enzymatic mastitis indicators of milk from dairy cows experimentally inoculated with Escherichia coli
}

\author{
L. P. Sørensen, ${ }^{* 1}$ R. M. Engberg, † P. Løvendahl, ${ }^{*}$ and T. Larsen† \\ *Department of Molecular Biology and Genetics, and \\ †Department of Animal Science, Aarhus University, Research Centre Foulum, DK-8830 Tjele, Denmark
}

\begin{abstract}
The aim of this study was to investigate the effect of a quantitative trait locus associated with mastitis caused by Escherichia coli, with one haplotype being more susceptible $(\mathrm{HH})$ and another being more resistant (HL) to $E$. coli mastitis, on the activity of 4 inflammatory related milk enzymes. In particular, we investigated the suitability of $\beta$-glucuronidase (GLU) as an early indicator of $E$. coli mastitis. Besides GLU, the enzymes L-lactate dehydrogenase (LDH), $N$-acetyl$\beta$-D-glucosaminidase (NAGase), and alkaline phosphatase were included. The study was conducted in an experimental setup with 31 Holstein cows divided into 4 groups representing repeated experiments and, within group, divided according to quantitative trait locus haplotype. All cows were inoculated with viable $E$. coli, and milk samples were collected 27 times from -6 to $396 \mathrm{~h}$ post- $E$. coli inoculation (PI). Activity of the 4 enzymes in milk, somatic cell count (SCC), daily milk yield, viable $E$. coli counts, and results of a semiquantitative polymerase chain reaction for pathogen detection, were all analyzed with a repeatability model. The response variables all expressed a strong reaction to the E. coli infection. Daily milk yield decreased significantly at $12 \mathrm{~h} \mathrm{PI}$ and bacteria counts increased 100-fold and peaked at $18 \mathrm{~h}$ PI, which was validated by PCR. Also, SCC started to increase at $12 \mathrm{~h}$ PI and increased on average 70 times; however, no significant differences in SCC level were detected between HH and HL cows at any sampling point. The enzymes LDH, NAGase, and alkaline phosphatase showed similar responses, with a significantly increased activity and higher peak values for the $\mathrm{HH}$ than the HL cows. Significant differences
\end{abstract}

Received November 5, 2014.

Accepted April 15, 2015.

${ }^{1}$ Corresponding author: LarsPeter.Sorensen@mbg.au.dk between $\mathrm{HH}$ and HL cows were detected at different time points for these 3 enzymes, but not after adjusting $P$-values for multiple testing. A different pattern was also observed for GLU, where HL cows expressed the highest peak activity. Indication of differences in GLU activity between the 2 haplotype groups was only seen at $60 \mathrm{~h}$ PI. It was concluded that $\mathrm{HL}$ and $\mathrm{HH}$ cows expressed similar response patterns after E. coli infection but with differences in the size and profile of the activity of the 4 enzymes. The enzyme GLU was an equally good indicator of $E$. coli mastitis compared with the other studied enzymes, although it showed a slower response compared with LDH and NAGase.

Key words: dairy cattle, mastitis indicator, milk enzyme, quantitative trait locus

\section{Short Communication}

Mastitis in dairy cattle has a serious economic effect due to production loss, treatment costs, increased labor, increased culling rate, and reduced milk quality (Halasa et al., 2007). Furthermore, mastitis reduces animal welfare and the use of antibiotics for therapy should be limited in light of increasing problems with microbial resistance against antibiotics. Management strategies seem to be the most effective means for controlling mastitis (Seegers et al., 2003). However, to improve genetic selection for mastitis resistance, considerable efforts have been put into the identification of QTL associated with mastitis, especially in the Nordic countries where phenotypic data on mastitis treatments is available (Klungland et al., 2001; Holmberg and Andersson-Eklund, 2004; Schulman et al., 2004; Lund et al., 2008). A QTL on bovine autosome 9 has been found to be associated with mastitis caused by Escherichia coli, with one haplotype being more susceptible and another being more resistant (Sørensen et al., 2008). Khatun et al. (2013) investigated the effect of this QTL on clinical and paraclinical disease phenotypes in an 
experimental setup where Holstein cows bearing haplotypes with either low (HL) or high $(\mathbf{H H})$ susceptibility to $E$. coli mastitis were inoculated with viable $E$. coli. The effect of this QTL was further investigated in the present study.

The invasion of pathogens into the bovine udder triggers an intramammary inflammatory response which causes a change in milk composition (Kitchen, 1981). Several milk components may be used as indicators for mastitis, SCC being the most common (Pyörälä, 2003); other indicators include inflammatory-related enzymes (Kitchen, 1981). The immunological contribution of these enzymes is not known (Hurley et al., 1987), but several studies have shown that milk enzymes can be useful as mastitis indicators. L-Lactate dehydrogenase (LDH; EC 1.1.1.27) is a nonlysosomal enzyme found in all cells and tissues in the body (Dixon and Webb, 1958). Lehmann et al. (2013) suggested that increased $\mathrm{LDH}$ activity in milk during an udder infection is caused by release from disrupted leukocytes and damaged epithelial cells but also from soluble LDH from blood because of alterations in the blood-milk barrier. Automatic inline measurement of LDH has successfully been used for mastitis detection in automated milking systems (Chagunda et al., 2006a). N-Acetyl$\beta$-D-glucosaminidase (NAGase; EC 3.2.1.52) also has potential as indicator of mastitis (Chagunda et al., 2006b). This enzyme is of lysosomal origin and released from neutrophils during phagocytosis and cell lysis, but especially from damaged epithelial cells during mastitis (Kitchen et al., 1984). Basic activity of alkaline phosphatase (AP; EC 3.1.3.1) in the mammary gland is associated with microsomal particles (Andrews, 1992). Heyneman and Burvenich (1992) suggested that increased AP activity during mastitis is related to enhanced expression of $\mathrm{AP}$ originating from leukocytes under direct or indirect influence of inflammatory mediators. Larsen et al. (2010) investigated the effect of AP as early indicator of $E$. coli LPS-induced mastitis. Distinction between LPS- and placebo $(\mathrm{NaCl})$-infused quarters was only possible for a limited time frame for AP, which suggests limited use for AP as indicator of mastitis. The lysosomal enzyme $\beta$-glucuronidase (GLU; EC 3.2.1.31) is released from cells participating in inflammatory response when they are stimulated. This enzyme may be an important indicator of mastitis because it is, in contrast to $\mathrm{LDH}$, NAGase, and AP, not released from epithelial cells (Perdigon et al., 1986). Fang et al. (1995) showed that GLU is also released from common mastitis pathogens, such as E. coli, Streptococcus uberis, and Streptococcus agalactiae, but not Staphylococcus aureus. Larsen and Aulrich (2012) suggested that GLU may not be a reliable mastitis indicator on its own because of a weaker correlation between GLU activity and SCC compared with the association between SCC and activity of LDH and NAGase. However, the combination with either LDH or NAGase proved inferior to the use of either LDH or NAGase alone.

The objectives of our study were to (1) investigate the suitability of GLU as early indicator of $E$. coli mastitis and (2) investigate whether Holstein cows bearing either HL or HH haplotypes for susceptibility to E. coli mastitis express differences in activity of GLU, LDH, NAGase, and AP. We expected that both HL and HH cows developed mastitis indicated by increasing bacterial count, SCC, and enzyme activity shortly after inoculation. We also expected that HL cows were better at suppressing the infection indicated by shorter time for the infection indicators to return to preinoculation level.

Data for our study was acquired from new analyses of milk samples collected in the experiment described in details by Khatun et al. (2013). Briefly, 31 first-parity Holstein cows were divided into 4 groups according to expected calving date: 2 groups in winter and 2 groups in summer. Within each group, cows were divided according to QTL haplotype. Groups 1, 3, and 4 consisted of $4 \mathrm{HH}$ and $4 \mathrm{HL}$ cows and group 2 consisted of $2 \mathrm{HH}$ and 5 HL cows. All cows were inoculated with a small dose of viable $E$. coli $(20-40 \mathrm{cfu})$ in the front quarter with the lowest SCC $(<100,000$ cells $/ \mathrm{mL})$ at $0 \mathrm{~h}, 4$ to 5 wk after calving. Milk samples were collected as foremilk samples before milking at $-6,0,3,6,12,18,24$, $36,48,60,72,84,96,108,120,132,144,156,168,180$, $192,204,216,228,240,300$, and 396 h post- $E$. coli inoculation (PI). The cows were milked twice a day, and daily milk yield $(\mathrm{kg})$ was recorded and milk samples were collected for SCC. Daily milk yield and SCC were available from -60 to $228 \mathrm{~h}$ PI at 24-h intervals.

Presence of $E$. coli cells were quantified using 2 different methods: (1) by bacteriological culturing as described by Buitenhuis et al. (2011) and subsequent quantification of viable counts (cfu) and (2) by a semiquantitative real-time PCR assay (PathoProof Mastitis PCR assay, Finnzymes Oy, Espoo, Finland). The PCR analyses were done at a central laboratory (Eurofins, Holstebro, Denmark) and results were provided as the number of PCR cycles (cycle threshold, Ct value) to reach a fixed fluorescence threshold as described by Koskinen et al. (2009). Thus, a lower Ct value indicates the presence of more bacteria. A detection threshold of $\mathrm{Ct}$ value $=37$ was used (Koskinen et al., 2009). The SCC analysis (cells $/ \mathrm{mL}$ ) was also done at a central laboratory (Eurofins) using flow cytometry (CombiFoss, Foss Electric, Hillerød, Denmark). Activities of the 4 milk enzymes were determined by kinetic, fluorometric methods. The activity of $\mathrm{LDH}(\mu \mathrm{mol} / \mathrm{min}$ per liter), 
was analyzed as described by Larsen (2005), the activity of NAGase ( $\mu \mathrm{mol} / \mathrm{min}$ per liter) and the activity of AP $(\mu \mathrm{mol} / \mathrm{min}$ per liter) were analyzed according to Larsen et al. (2010). The method for analyzing GLU (nmol/min per liter) was described by Larsen and Aulrich (2012).

All phenotypes were analyzed using the following repeatability model:

$$
\mathbf{y}=\mathbf{X b}+\mathbf{Z}_{1} \mathbf{a}+\mathbf{Z}_{2} \mathbf{m}+\mathbf{e}
$$

where $\mathbf{y}$ is a vector of phenotypes (activity of $\mathrm{LDH}$, NAGase, AP, and GLU, ln-transformed Ct values and SCC, log-transformed viable E. coli counts, and daily milk yield), $\mathbf{b}$ is a vector of fixed effects (group and haplotype), $\mathbf{a}$ is vector of random cow effects, $\mathbf{m}$ is a vector of random measurement effects, $\mathbf{e}$ is a vector of residual effects, and $\mathbf{X}, \mathbf{Z}_{1}$, and $\mathbf{Z}_{2}$ are corresponding incidence matrices. Because of the nonequidistant sampling times, the correlation within cow was modeled using a Gaussian spatial covariance structure. Data were analyzed using the MIXED procedure in SAS (version 9.3, SAS Institute Inc., Cary, NC). No changes in the levels of the response variables were observed after $192 \mathrm{~h}$ PI; thus, only phenotypes from 0 to $192 \mathrm{~h}$ PI were included in the analyses to avoid noise contribution from phenotypes recorded after $192 \mathrm{~h}$ PI. This resulted in 19 pairwise comparisons between HL and HH cows. The significance threshold was adjusted accordingly using a Bonferroni correction, $p^{*} \leq \frac{\alpha}{n}$, so that the adjusted probability threshold becomes $p^{*} \leq 0.0026$ at a given $\alpha=0.05$ and $n=19$. Mean time profiles of the indicator variables were created using data from all cows without considering haplotype. Also, Pearson correlation coefficients among the response variables were estimated across all cows and using the entire experimental period.

Khatun et al. (2013) indicated that a haplotype effect was seen in SCC restitution. However, this was not tested statistically. We tested this by adding time as a covariate in the previous model and tested whether the slope of the response variables on the time trajectory were statically different between HL and HH cows. The slopes were established between time of peak value and time, where response variables were assumed to have reached a stable level similar to PI level. Stable levels were determined from the time profiles and assumed to be $132 \mathrm{~h}$ PI for LDH, AP, and viable counts of E. coli; $156 \mathrm{~h}$ PI for NAGase and daily milk yield; $204 \mathrm{~h}$ PI for GLU; $192 \mathrm{~h}$ PI for SCC; and $144 \mathrm{~h}$ PI for the Ct values.

All cows inoculated with viable $E$. coli developed acute mastitis. The infection also caused an increase

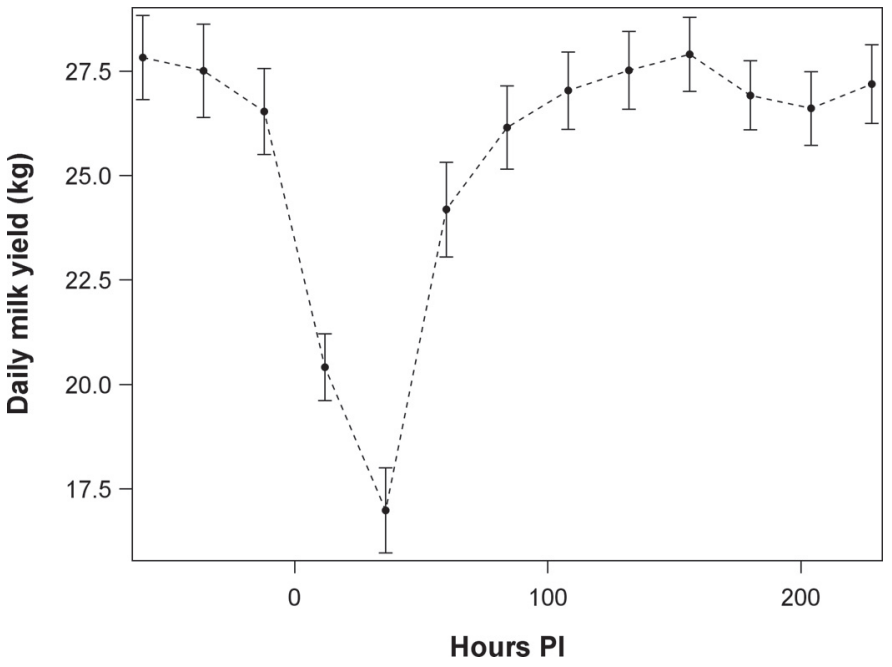

Figure 1. Overall average milk yield $(\mathrm{kg})$ and SD from Escherichia coli-inoculated cows from -60 to $228 \mathrm{~h}$ after inoculation. PI $=$ postinoculation.

in body temperature and heart rate and decreased feed intake and daily milk yield (Figure 1). Using $-12 \mathrm{~h}$ PI as control, a significant $(P<0.0001)$ decrease in daily milk yield of $5.8 \mathrm{~kg}$ was observed at $12 \mathrm{~h}$ PI. The largest decrease of $9.3 \mathrm{~kg}$ was observed at $36 \mathrm{~h} \mathrm{PI}$, and at $84 \mathrm{~h}$ PI the milk yield was back to the control level $(0$ h). No significant $(P>0.05)$ differences in daily milk yield between HL and HH cows were observed during the trial period.

A large increase was observed for all mastitis indicator variables (decrease for $\mathrm{Ct}$ values) following inoculation of E. coli (Figures 2 to 7 ). The bacteria started to multiply shortly after inoculation and peaked at $18 \mathrm{~h}$ PI, with approximately a 100 -fold increase relative to inoculation level at $0 \mathrm{~h}$ (Figure 2). After this time point, viable $E$. coli counts decreased fast and were close to zero after $132 \mathrm{~h}$ PI. The HL cows peaked at a slightly higher level, but no significant $(P>0.05)$ differences were observed at any time point during the trial period between the 2 haplotypes. The $\mathrm{Ct}$ values from the PCR analyses resembled bacterial counts closely and were lowest at $12 \mathrm{~h} \mathrm{PI}$ (Figure 2). No bacteria were detected after $132 \mathrm{~h}$ PI given the Ct threshold of 37. Again, HL cows had a slightly lower minimum value but were not significantly different from the $\mathrm{HH}$ cows $(P>0.05)$. The $E$. coli infection resulted in a drastic increase in SCC level for cows bearing either haplotype (Figure 3), and large variation among the cows was seen during the infection. Somatic cell count level started to increase around $12 \mathrm{~h}$ PI and peaked at $48 \mathrm{~h}$ PI with a 70-fold average increase compared with $-12 \mathrm{~h}$ PI level. Differences in SCC level between the 2 haplotype groups were not significant $(P>0.05)$ at any time point. 


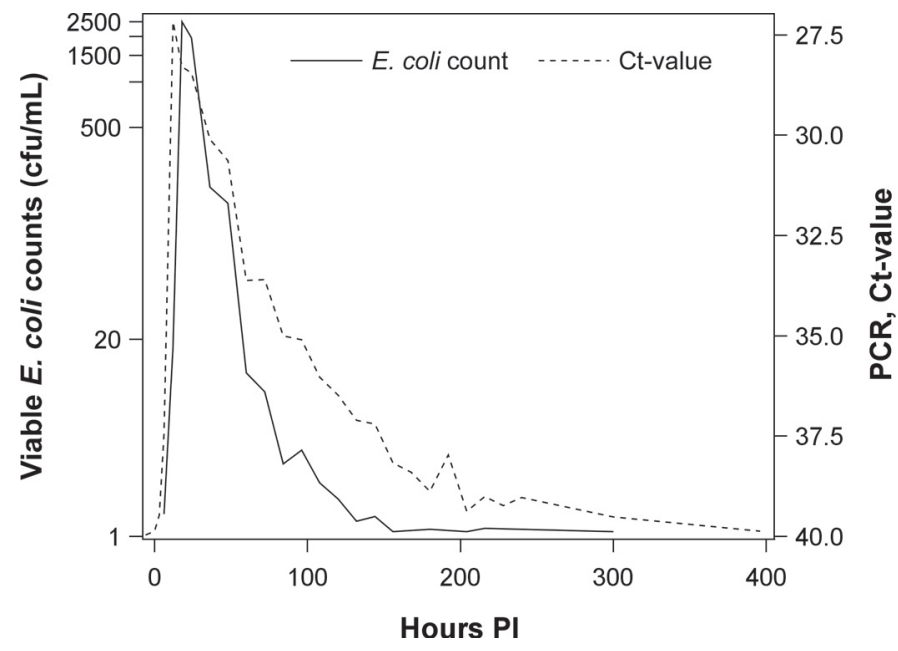

Figure 2. Overall means of viable Escherichia coli counts and cycle threshold $(\mathrm{Ct})$ values (SD not shown) from $E$. coli-inoculated cows from -6 to $396 \mathrm{~h}$ after inoculation. Viable $E$. coli counts are shown on $\log _{10}$-scale and secondary y-axis (Ct values) is reversed to facilitate comparison between the 2 variables. PI $=$ postinoculation.

Common for all 4 enzymes after E. coli infection was a large increase in activity a few hours PI and large variation among the cows during the infection period. The activity of LDH (Figure 4) was significantly different from the 0-h level at 18 to $72 \mathrm{~h}$ and 18 to $108 \mathrm{~h}$ PI for $\mathrm{HH}$ and HL cows, respectively (Table 1). Activity for the $\mathrm{HH}$ cows peaked at $18 \mathrm{~h} \mathrm{PI}$, with a response of $68.5 \mu \mathrm{mol} / \mathrm{min}$ per liter $(P<0.0001)$ compared with the 0 -h level. The HL cows peaked later at $36 \mathrm{~h}$ with a slightly lower response of $59.0 \mu \mathrm{mol} / \mathrm{min}$ per liter $(P$ $<0.0001$ ) compared with the 0-h level. A significant difference between the 2 haplotype groups was observed $18 \mathrm{~h}$ PI only, with a higher activity of $21.4 \mu \mathrm{mol} / \mathrm{min}$ per liter $(P=0.042)$ for the HH cows. However, when considering the significance threshold for multiple testing, this difference was deemed nonsignificant. The activity of NAGase (Figure 5) peaked at $24 \mathrm{~h} \mathrm{PI}$, with a higher activity of 33.6 and $49.2 \mu \mathrm{mol} / \mathrm{min}$ per liter $(P<0.0001)$ compared with the 0 -h level for HL and $\mathrm{HH}$ cows, respectively. Significant differences from the 0-h level were seen from 18 to $96 \mathrm{~h}$ and 18 to 108 h PI for HH and HL cows, respectively (Table 1). A significant difference $(P=0.022)$ between $\mathrm{HL}$ and $\mathrm{HH}$ cows was seen only at $24 \mathrm{~h} \mathrm{PI}$, with a higher activity of $15.0 \mu \mathrm{mol} / \mathrm{min}$ per liter for the HH cows. Again, considering the significance threshold, this difference was nonsignificant. Regarding AP (Figure 6), a significantly increased activity was observed from 18 to $72 \mathrm{~h}$ PI for HL cows, but only from 18 to $48 \mathrm{~h}$ PI for the HH cows compared with the 0-h level (Table 1). Both haplotype groups peaked later at $48 \mathrm{~h}$ PI compared with LDH and NAGase, and resulted in an increase in activity of $\mathrm{AP}$ of 772.8 and $482.0 \mu \mathrm{mol} / \mathrm{min}$ per liter $(P<0.0001)$ for $\mathrm{HH}$ and HL cows, respectively, compared with the 0 -h level. A significant difference between HH and HL cows was observed at $48 \mathrm{~h}$ PI $(P<0.019)$, although not significant when considering multiple testing. The activity of GLU (Figure 7) responded differently compared with the other enzymes. Peak activity was observed at $36 \mathrm{~h}$ PI for both haplotypes; in contrast to LDH, NAGase, and AP, for GLU an increase of $117.8 \mathrm{nmol} / \mathrm{min}$ per liter compared with the 0 -h level was seen for the HL cows compared with $97.2 \mathrm{nmol} / \mathrm{min}$ per liter for the HH cows. Significant differences from the 0-h level were seen from 18 to $84 \mathrm{~h}$ and 18 to $96 \mathrm{~h}$ PI for HL and HH cows, respectively. Differences in GLU activity between the 2 haplotypes were only significant $(P<0.0066)$ at $60 \mathrm{~h}$ PI, but were nonsignificant when accounting for multiple testing.

Associations between the analyzed milk enzymes, other mastitis indicators, and milk yield are presented in Table 2 and were all significantly different from zero $(P<0.0001)$. The correlations between the 4 enzymes were overall strong and positive $(\mathrm{r}=0.65$ to 0.85$)$, and AP generally had the lowest correlation with the remaining 3 enzymes. The correlations between viable counts of $E$. coli and enzyme activities were moderately positive $(\mathrm{r}=0.55$ to 0.65$)$, with the strongest correlation to LDH and the weakest to GLU. The correlations between $\mathrm{Ct}$ values and enzymes activities were of similar magnitude ( $\mathrm{r}=-0.61$ to -0.53 ) but negative, as expected, for the $\mathrm{Ct}$ scale. The correlation between viable counts of $E$. coli and $\mathrm{Ct}$ values was strongly negative $(\mathrm{r}=-0.80)$ indicating good agreement between the 2 methods. The association between SCC

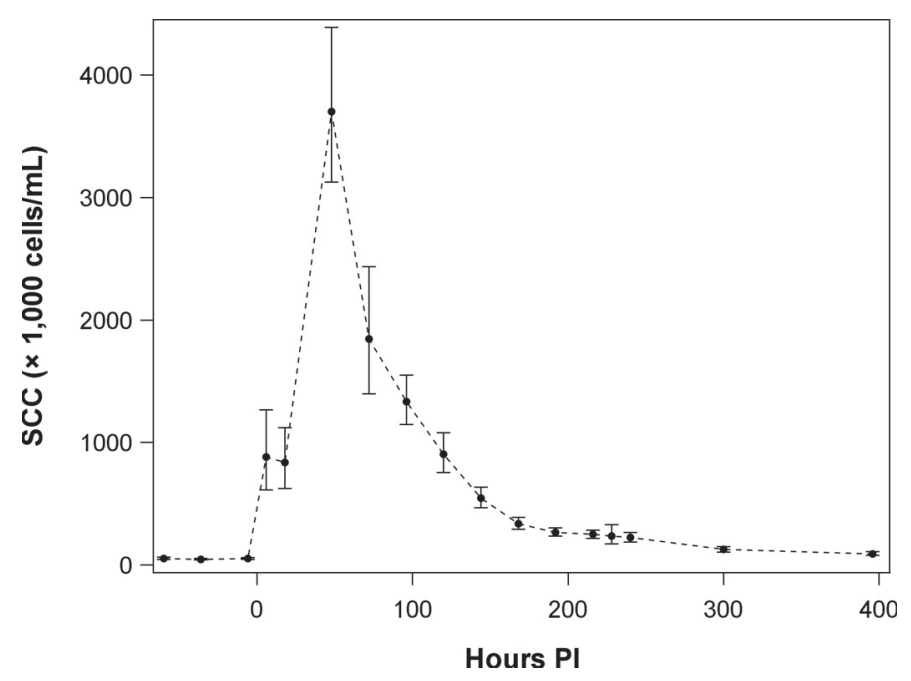

Figure 3. Overall average SCC and SD from Escherichia coli-inoculated cows from -60 to $228 \mathrm{~h}$ after inoculation. $\mathrm{PI}=$ postinoculation. 


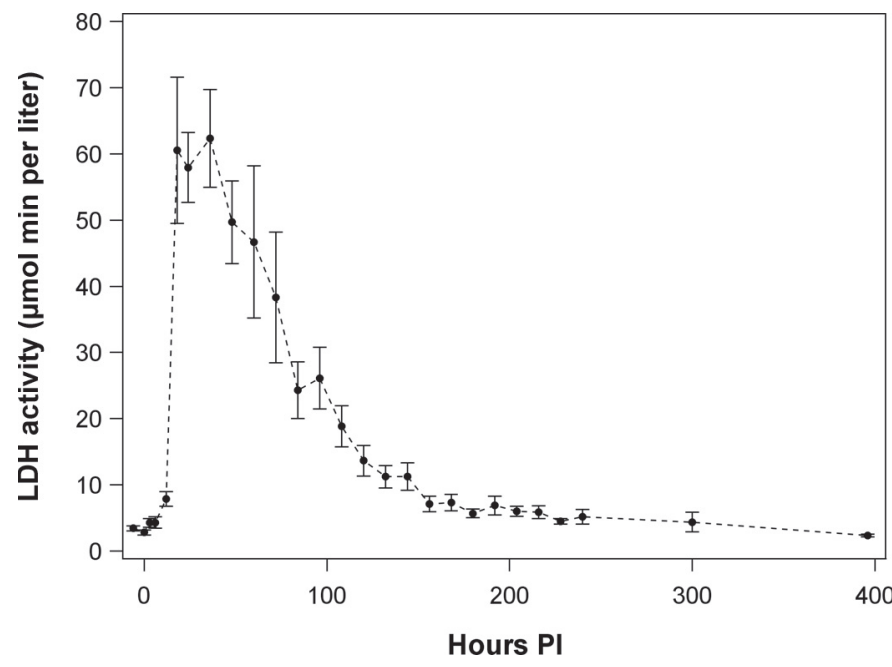

Figure 4. Overall average activity of L-lactate dehydrogenase (LDH) and SD from Escherichia coli-inoculated cows from -6 to 396 $\mathrm{h}$ after inoculation. $\mathrm{PI}=$ postinoculation.

and enzyme activity was similar for the 4 enzymes $(\mathrm{r}=$ 0.42 to 0.50 ), with the strongest correlation to NAGase activity. Overall, the correlations between daily milk yield and the remaining response variables were low and negative (positive for $\mathrm{Ct}$ values).

Regarding the effect of haplotype on the recovery of the indicator variables, we were not able to detect any significant differences in recovery slopes from peak level to PI level time between the 2 haplotype groups.

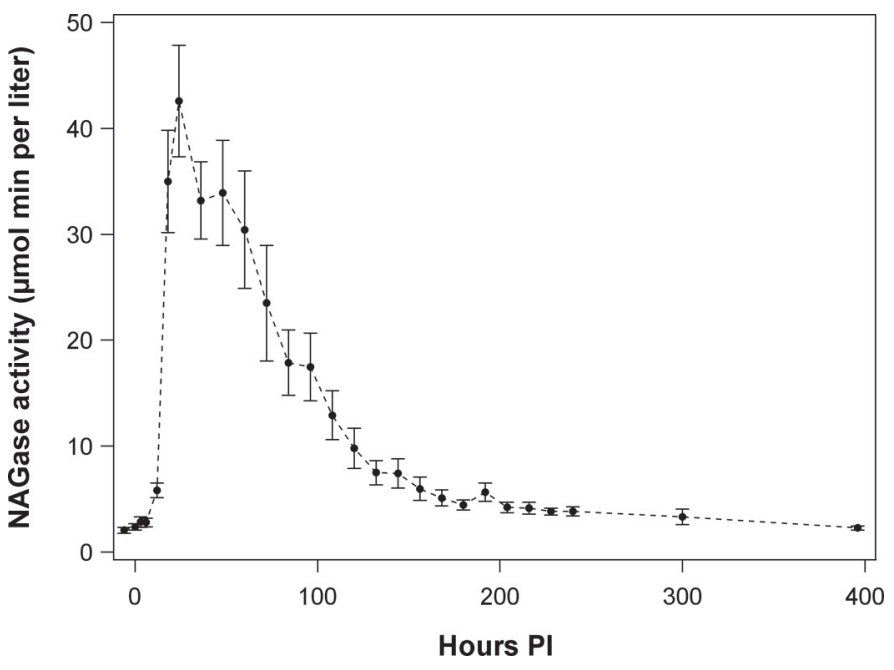

Figure 5. Overall average activity of $N$-acetyl- $\beta$-D-glucosaminidase (NAGase) and SD from Escherichia coli-inoculated cows from -6 to $396 \mathrm{~h}$ after inoculation. PI = postinoculation.

The milk enzymes, including GLU, analyzed in our study were equally suitable as early warning indicators for E. coli mastitis. They all showed strong and rapid responses to the presence of bacteria from $18 \mathrm{~h}$ PI onwards, and they all showed differences between QTL haplotypes, although the latter effect could not be established when adjusting for multiple testing. Also, it should be noted that peak levels of the enzymes were reached at slightly different time points, which

Table 1. Least squares means differences ( $P$-values in parentheses) from activity level at $0 \mathrm{~h}$ for L-lactate dehydrogenase (LDH; $\mu$ mol/min per liter), $N$-acetyl- $\beta$-D-gulcosaminidase (NAGase; $\mu \mathrm{mol} / \mathrm{min}$ per liter), alkaline phosphatase (AP; $\mu \mathrm{mol} / \mathrm{min}$ per liter), and $\beta$-glucuronidase (GLU; $\mathrm{nmol} / \mathrm{min}$ per liter) for cows with haplotypes for high (HH) and low (HL) susceptibility to Escherichia coli mastitis

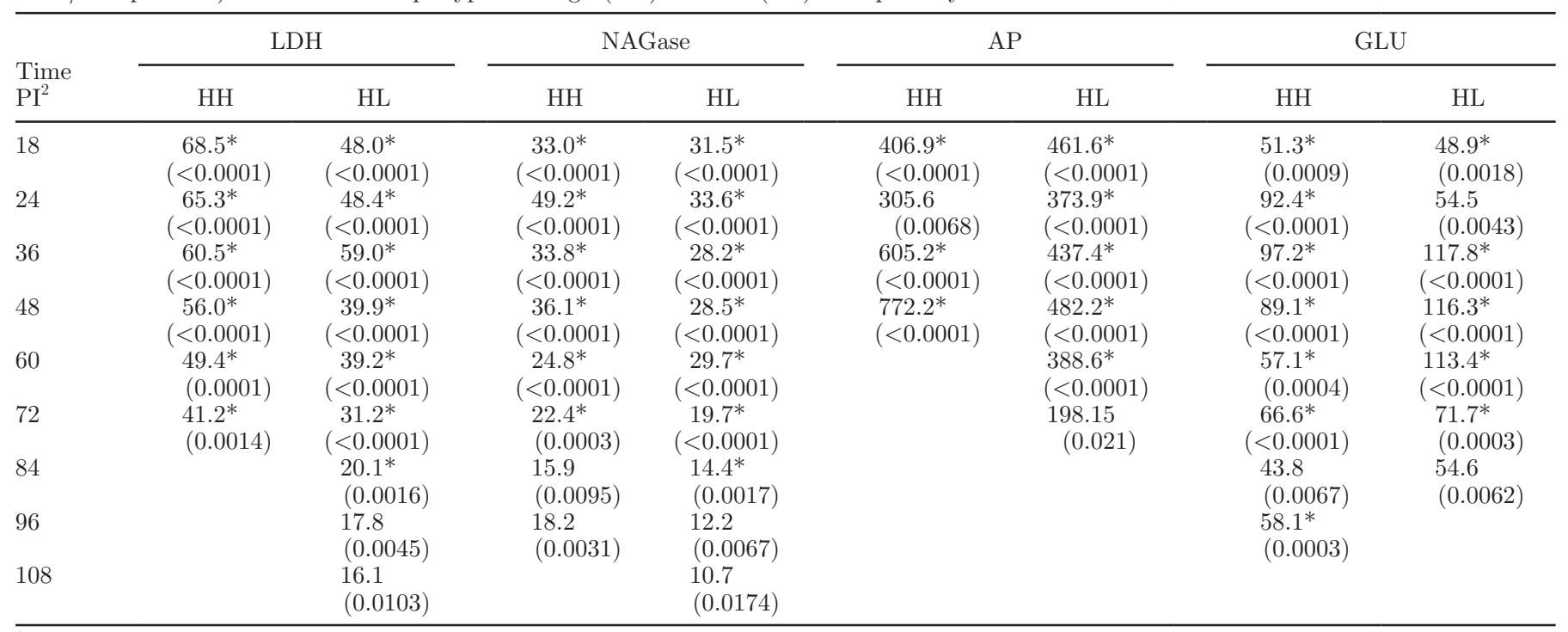

${ }^{1}$ Only significant results are shown.

${ }^{2}$ Post- $E$. coli inoculation (in hours).

*Significant after adjustment for multiple testing. 
Table 2. Pearson correlations between milk enzyme activity of L-lactate dehydrogenase (LDH), $N$-acetyl- $\beta$-D-glucosaminidase (NAGase), alkaline phosphatase (AP), $\beta$-glucuronidase (GLU), other mastitis indicators such as viable Escherichia coli counts (cfu),cycle threshold (Ct) values, SCC, and milk yield ${ }^{1}$

\begin{tabular}{|c|c|c|c|c|c|c|c|}
\hline Item & \multicolumn{7}{|c|}{ Response variable } \\
\hline $\mathrm{LDH}$ & $\begin{array}{r}0.85(782) \\
{[0.83 .087]}\end{array}$ & $\begin{array}{c}0.65(782) \\
{[0.61 \cdot 069]}\end{array}$ & $\begin{array}{c}0.73(782) \\
{[069 \cdot 076]}\end{array}$ & $\begin{array}{c}0.65(779) \\
{[060 \cdot 069]}\end{array}$ & $-0.61(766)$ & $0.48(333)$ & $-0.29(360)$ \\
\hline \multirow[t]{2}{*}{ NAGase } & & $0.71(782)$ & $0.79(782)$ & $0.64(779)$ & $-0.61(766)$ & $0.50(333)$ & $-0.25(360)$ \\
\hline & & {$[0.67 ; 0.74]$} & {$[0.76 ; 0.81]$} & {$[0.59 ; 0.68]$} & {$[-0.65 ;-0.56]$} & {$[0.41 ; 0.57]$} & {$[-0.34 ;-0.15]$} \\
\hline $\mathrm{AP}$ & & & $0.70(782)$ & $0.57(779)$ & $-0.52(766)$ & $0.38(333)$ & $-0.25(360)$ \\
\hline GLU & & & & {$[0.50 ; 0.59]$} & {$[-0.58 ;-0.47]$} & {$[0.33 ; 0.50]$} & {$[-0.32 ;-0.12]$} \\
\hline \multirow{2}{*}{$\mathrm{cfu}$} & & & & & $-0.80(764)$ & $0.43(334)$ & $-0.32(360)$ \\
\hline & & & & & {$[-0.83 ;-0.78]$} & {$[0.34 ; 0.51]$} & {$[-0.41 ;-0.23]$} \\
\hline \multirow[t]{2}{*}{ Ct value } & & & & & & $-0.64(331)$ & $0.20(355)$ \\
\hline & & & & & & {$[-0.70 ;-0.57]$} & {$[0.10 ; 0.30]$} \\
\hline \multirow[t]{2}{*}{$\mathrm{SCC}$} & & & & & & & $-0.44(276)$ \\
\hline & & & & & & & {$[-0.53 ;-0.34]$} \\
\hline
\end{tabular}

$\overline{{ }^{1} \text { Numbers represent Pearson correlation coefficients among the analyzed variables across all cows and experimental period; figures in parentheses }}$ are numbers of observations. Values in brackets show $95 \%$ CI for the correlation estimates.

may have an effect of the usefulness of the enzymes as early warning indicators for $E$. coli mastitis if used in automated milking systems (timely alert). No effects of QTL haplotype on viable $E$. coli counts, Ct-values, or SCC level were observed. Based on this, we speculated that QTL mechanisms that do not affect SCC level, but rather SCC function or ability of mammary epithelial cells to resist damage, are responsible for the observed activity patterns of the investigated enzymes.

For LDH, NAGase, and AP, the HL haplotype showed a weaker response to E. coli infection compared with the $\mathrm{HH}$ haplotype. In contrast, the activity of GLU was highest in the HL cows. This may indicate

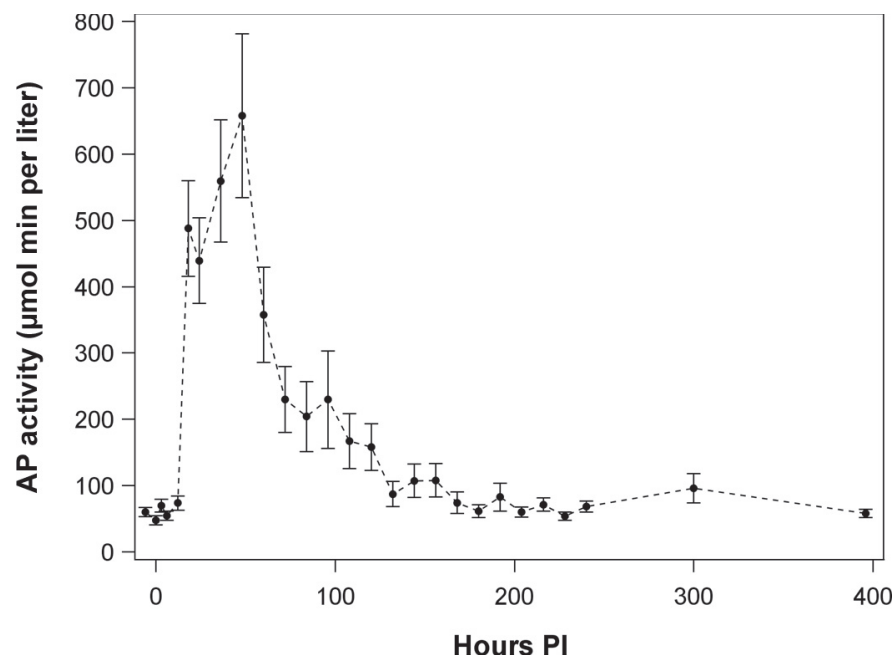

Figure 6. Overall average activity of alkaline phosphatase (AP) and SD from Escherichia coli-inoculated cows from -6 to $396 \mathrm{~h}$ after inoculation. $\mathrm{PI}=$ postinoculation. that the source of enzyme activity is different for GLU compared with the remaining enzymes. Some E. coli strains related to mastitis in dairy cows have been shown to release great amounts of GLU (Fang et al., 1995), which is important for the ability of the bacteria to cleave lactose into glucose and galactose as an energy source. Macrophages and polymorphonuclear neutrophils (PMN) release all 4 enzymes (e.g., Schorlemmer et al., 1977), whereas mammary epithelial cells are not described to be a source of GLU release (Hurley et al., 1987). In contrast, mammary epithelial cells seem to be a major source for the release of LDH, NAGase, and AP, indicating mammary epithelium damage (Kitchen

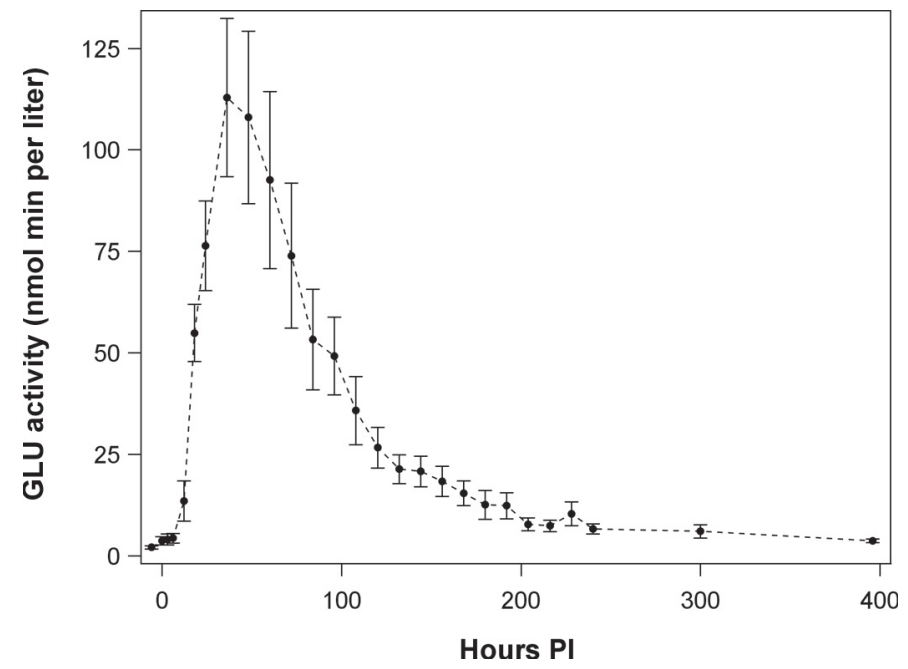

Figure 7. Overall average activity of $\beta$-glucuronidase (GLU) and SD from Escherichia coli-inoculated cows from -6 to $396 \mathrm{~h}$ after inoculation. PI = postinoculation. 
et al., 1978; Kitchen, 1981). Additionally, blood-derived $\mathrm{LDH}$ is an important contributor to LDH activity in the mammary gland during mastitis (Lehmann et al., 2013). Khatun et al. (2013) found that the QTL haplotypes were associated with a difference in leukocyte kinetics, with HL cows having faster blood PMN recruitment and a tendency for faster SCC recovery and a milder clinical response (lower heart rate and body temperature) than the HH cows. Hence, the combined results from Khatun et al. (2013) and the present study indicate that the higher activity of LDH, NAGase, and AP for the $\mathrm{HH}$ cows can mainly be explained by increased damage to the mammary epithelial cells. Because no differences in viable $E$. coli counts were found between the 2 haplotypes, the release of GLU from $E$. coli cells is expected to be similar for the 2 haplotype groups. Thus, the higher GLU activity for the HL cows can be explained by increased release of GLU from macrophages and PMN compared with the $\mathrm{HH}$ cows. Alternatively, one might speculate that the $\mathrm{HH}$ haplotype (cow) produces (more) inhibitory substances against bacterial GLU activity; however, we have no information that can confirm such speculations. The composition of SCC may also be different in the HL cows, resulting in a better capability to deal with an $E$. coli infection. However, in the present study, it could not be confirmed that the increased release was due to the presence of more PMN in the udder or increased release from individual macrophages and PMN. Based on the results from the present study, it is not clear whether GLU may be used for identification of specific pathogens related to mastitis, or vice versa, be used to exclude strains of bacteria as in the case of Staph. aureus. The GLU activity of E. coli proved to be considerable, and the exact origin of the GLU activity will require more detailed studies.

The associations between the 4 milk enzymes, in general, were stronger than those found by Larsen and Aulrich (2012), who collected milk samples from randomly selected cows. In the present study, all cows had E. coli mastitis, were of the same breed and parity, and at similar stages of lactation. This created a more homogenous group of cows, which may explain the higher correlations between the enzyme activities. Also, the correlations between enzyme activity and SCC were stronger in the present study. Viable E. coli counts and the PCR method for determining the presence of bacteria were strongly correlated. The PCR method responded earlier than the culturing method and detected the presence of bacteria for a longer time compared with the culturing method. This is because bacteria already killed by the mammary immune response are detected by the PCR method and not by the culturing method. In the present study, in contrast to suggestions from Khatun et al. (2013), any differences between haplotypes in the ability to recover from the $E$. coli infection could not be detected based on the used mastitis indicators. The differences were numerically small and would require a much larger sample size to become detectable.

In conclusion, our study shows that, in general, cows bearing $\mathrm{HH}$ or HL haplotypes follow a similar response pattern when inoculated with viable $E$. coli, but differences in response time and the size of the response exist for enzyme-based mastitis indicators such as $\mathrm{LDH}$, NAGase, AP, and GLU. The milk enzyme GLU was an equally good indicator, with a response profile very similar to that of LDH, NAGase, and AP. However, LDH and NAGase responded faster compared with GLU and AP, which made them superior as mastitis indicators in an automated mastitis-detection system. Further examinations are necessary to finally show whether a genetic association of GLU activities with different haplotypes of the bovine autosome 9 QTL exists or not.

\section{ACKNOWLEDGMENTS}

This project was supported by the Danish Milk Levy Fund (Skejby, Denmark) as part of the project "Use of inline measurements for genetic improvement of mastitis resistance in dairy cattle."

\section{REFERENCES}

Andrews, A. T. 1992. Indigenous enzymes in milk. Pages 322-325 in Advanced Dairy Chemistry. Vol. 1-Proteins. P. F. Fox, ed. Elsevier Applied Science, London, UK.

Buitenhuis, B., C. M. Røntved, S. M. Edwards, K. L. Ingvartsen, and P. Sørensen. 2011. In depth analysis of genes and pathways of the mammary gland involved in the pathogenesis of bovine Escherichia coli-mastitis. BMC Genomics 12:130.

Chagunda, M. G. G., N. C. Friggens, M. D. Rasmussen, and T. Larsen. 2006a. A model for detection of individual cow mastitis based on an indicator measured in milk. J. Dairy Sci. 89:2980-2998.

Chagunda, M. G. G., T. Larsen, M. Bjerring, and K. L. Ingvartsen. 2006b. L-Lactate dehydrogenase and N-acetyl- $\beta$-Dglucoasaminidase activities in bovine milk as indicators of nonspecific mastitis. J. Dairy Res. 73:431-440.

Dixon, M., and E. C. Webb. 1958. Page 202 in Enzymes. Academic Press, New York, NY.

Fang, W., M. Vikerpuur, and M. Sandholm. 1995. A fluorometric $\beta$-glucuronidase assay for analysis of bacterial growth in milk. Vet. Microbiol. 46:361-367.

Halasa, T., K. Huijps, O. Østerås, and H. Hogeveen. 2007. Economic effects of bovine mastitis and mastitis management: A review. Vet. Q. 29:18-31.

Heyneman, R., and C. Burvenich. 1992. Kinetics and characteristics of bovine neutrophil alkaline phosphatase during acute Escherichia coli mastitis. J. Dairy Sci. 75:1826-1834.

Holmberg, M., and L. Andersson-Eklund. 2004. Quantitative trait loci affecting health traits in Swedish dairy cattle. J. Dairy Sci. $87: 2653-2659$

Hurley, W. L., T. M. McKee, and D. R. Cue. 1987. Lysosomal enzymes in bovine mammary leukocytes during the nonlactating period. Vet. Immunol. Immunopathol. 16:95-105. 
Khatun, M., P. Sørensen, H. B. H. Jørgensen, G. Sahana, L. P. Sørensen, M. S. Lund, K. L. Ingvartsen, A. J. Buitenhuis, J. Vilkki, M. Bjerring, J. R. Thomasen, and C. M. Røntved. 2013. Effects of Bos Taurus autosome 9-located quantitative loci haplotypes on the disease phenotypes of dairy cows with experimentally induced Escherichia coli mastitis. J. Dairy Sci. 96:1820-1833.

Kitchen, B. J. 1981. Review of the progress of dairy science: bovine mastitis: Milk compositional changes and related diagnostic tests. J. Dairy Res. 48:167-188.

Kitchen, B. J., G. Middletion, W. S. Kwee, and R. J. Andrews. 1984. $\mathrm{N}$-acetyl- $\beta$-D-glucosaminidase (NAGase) levels in bulk herd milk. J. Dairy Res. 51:227-232.

Kitchen, B. J., G. Middleton, and M. Salmon. 1978. Bovine milk $\mathrm{N}$-acetyl- $\beta$-D-glycosaminidase and its significance in the detection of bovine mastitis. J. Dairy Res. 45:15-20.

Klungland, H., A. Sabry, B. Heringstad, H. G. Olsen, L. Gomez-Raya, D. I. Våge, I. Olsaker, J. Ødegård, G. Klemetsdal, N. Schulman, J. Vilkki, J. Ruane, M. Aasland, K. Rønningen, and S. Lien. 2001. Quantitative trait loci affecting clinical mastitis and somatic cell count in dairy cattle. Mamm. Genome 12:837-842.

Koskinen, M. T., J. Holopainen, S. Pyörälä, P. Bredbacka, A. Pitkälä, H. W. Barkema, R. Bexiga, J. Roberson, L. Sølverød, R. Piccinini, D. Kelton, H. Lehmusto, S. Niskala, and L. Salmikivi. 2009. Analytical specificity and sensitivity of a real-time polymerase chain reaction assay for identification of bovine mastitis pathogens. J. Dairy Sci. 92:952-959.

Larsen, T. 2005. Determination of lactate dehydrogenase (LDH) activity in milk by a fluorometric assay. J. Dairy Res. 72:209-216.

Larsen, T., and K. Aulrich. 2012. Optimizing the fluorometric $\beta$-glucuronidase assay in ruminant milk for a more precise determination of mastitis. J. Dairy Res. 79:7-15.
Larsen, T., C. M. Røntved, K. L. Ingvartsen, L. Vels, and M. Bjerring. 2010. Enzyme activity and acute phase proteins in milk utilized as indicators of acute clinical E. coli LPS-induced mastitis. Animal 4:1672-1679.

Lehmann, M., O. Wellnitz, and R. M. Bruckmaier. 2013. Concominant lipopolysaccharide-induced transfer of blood-derived components including immunoglobulins into milk. J. Dairy Sci. 96:889-896.

Lund, M. S., B. Guldbrandtsen, A. J. Buitenhuis, B. Thomasen, and C. Bendixen. 2008. Detection of quantitative loci in Danish Holstein cattle affecting clinical mastitis, somatic cell score, udder confirmation traits, and assessment of associated effects on milk yield. J. Dairy Sci. 91:4028-4036.

Perdigon, G., M. Medici, M. Cecilia, M. E. Nader de Macios, R. Haedo, G. Oliver, and A. A. Pesce de Ruiz Holgado. 1986. Significance of the presence of bovine milk $\beta$-glucuronidase in mastitis detection. J. Dairy Sci. 69:27-31.

Pyörälä, S. 2003. Indicators of inflammation in the diagnosis of mastitis. Vet. Res. 34:565-578.

Schorlemmer, H. U., R. Burger, W. Hylton, and A. C. Allison. 1977. Induction of lysosomal enzyme release from culture macrophages by dextran sulfate. Clin. Immunol. Immunopathol. 7:88-96.

Schulman, N. F., S. M. Viitala, D. J. de Koning, J. Virta, A. MäkiTanila, and J. Vilkki. 2004. Quantitative trait loci for health traits in Finnish Ayrshire cattle. J. Dairy Sci. 87:443-449.

Seegers, H., C. Fourichon, and F. Beaudeau. 2003. Production effects related to mastitis and mastitis economics in dairy cattle herds. Vet. Res. 34:475-491.

Sørensen, L. P., B. Guldbrandtsen, J. R. Thomasen, and M. S. Lund. 2008. Pathogen-specific effects of quantitative trait loci affecting clinical mastitis and somatic cell count in Danish Holstein cattle. J. Dairy Sci. 91:2493-2500. 